\title{
COMMUNITY ORGANIZATIONAL LEARNING: CASE STUDIES ILLUSTRATING A THREE- DIMENSIONAL MODEL OF LEVELS AND ORDERS OF CHANGE
}

\author{
Douglas D. Perkins, Kimberly D. Bess, Daniel G. Cooper, \\ Diana L. Jones, Theresa Armstead, and Paul W. Speer \\ Program in Community Research $\mathcal{E}$ Action, Vanderbilt University
}

\begin{abstract}
We present a three-dimensional cube framework to help community organizational researchers and administrators think about an organization's learning and empowerment-related structures and processes in terms of firstorder (incremental or ameliorative) and second-order (transformative) change at the individual, organizational, and community levels. To illustrate application of the framework, case studies of three different types of exemplary nonprofit organizations (a participatory neighborhood planning organization, a grassroots faith-based social action coalition, and a larger community-based human service agency) were based on qualitative interviews and participant observations. Our analysis, rooted in organizational learning theory, suggests that organizations that empower staff and volunteers through opportunities for learning and participation at the individual level are better able to succeed in terms of organizational-level learning and transformation. Community-level change is particularly difficult but must be made a more explicit goal. Learning that can lead to second-order change at each level must help participants engage in critical
\end{abstract}

\footnotetext{
We thank (a) the organizations that participated in the survey and especially the in-depth interviews for their staff time and honesty; (b) the students in three service-learning classes who conducted the surveys and many of the interviews; (c) Scot Evans, Carrie Hanlin, and Isaac Prilleltensky for their participation in the project and contribution of ideas to this paper; (d) the project's Community Advisory Board for their helpful input; and (e) the anonymous reviewers for their comments, which strengthened this article in many ways. This research was supported by a grant from the Vanderbilt University Learning Sciences Institute to Douglas D. Perkins, Paul W. Speer, and Daniel Cornfield.

Correspondence to: Douglas D. Perkins, Center for Community Studies, HOD Dept., Peabody College, Vanderbilt University, Nashville, TN 37203-5701. E-mail: d.perkins@vanderbilt.edu
} 
analysis of (a) the organization's demonstrated goals and values; (b) the power relationships implicit in decision making at each level; (c) the interdependent role of participant stakeholders and organizations as part of a complex, community-wide (or larger) system; and $(d)$ how to work toward transformative change of all of the above. (C) 2007 Wiley Periodicals, Inc.

Nonprofit community organizations have traditionally provided a public safety net and are widely acknowledged as working at the forefront of community problem solving. They have served as the nexus for individuals to come together to address community needs and build social capital. Yet, fiscal policies—at all levels of government-have exacerbated social, economic, and political problems for all communities, thus increasing the complexity of challenges confronted by nonprofit organizations. Such a context has forced nonprofits to both think and act differently as they work to increase their capacity to target the root causes of the problems they seek to address (De Vita \& Fleming, 2001; McHargue, 2003). This situation is especially dire for small community organizations that operate in high-need, low-resource environments, on limited budgets, while relying heavily on volunteers and other external resources that are also limited, unstable, and difficult to access (Hager, 2001).

Thinking and acting differently in organizations may occur either superficially or more fundamentally, or what has been called first- and second-order change, respectively (Watzlawick, Weakland, \& Fisch, 1974). First-order change affects just part of the system (e.g., change in personnel or programs) while leaving the underlying structure, cultural values, and purpose of the system intact. At best, it may result in incremental, ameliorative, or evolutionary change. In contrast, second-order change implies a paradigm shift; it is transformative, or revolutionary, change in the system itself (i.e., in the relationships among its parts or in its basic goals or processes). We argue that such orders of change may apply to any level of analysis, including individuals, organizations, and communities, and that those levels are interdependent. For example, in order to become more effective and efficient, organizations need empowered leaders, workers, and volunteers who are ready and able to learn, can think critically and systemically, and are adaptable to change. Likewise, significant community-level change may depend on the learning, empowerment, and transformation of the organizations that serve the community.

Thus, our purposes are to better understand (a) how learning occurs at multiple levels in community organizations, (b) how such learning may be related to expanding the capacity of organizations for empowering and systemic second-order change, and (c) how such transformative changes are related across the individual, organizational, and community levels. We will present a three-dimensional framework for first- and secondorder change at each of those levels and three case studies of different kinds of nonprofit organizations to illustrate the application of the framework.

Community psychologists have repeatedly called for the field to pay more attention to the theories, research, and interventions of organizational psychology and organization development (Keys \& Frank, 1987; Shinn \& Perkins, 2000). Although the field has focused intently on the programs and services that organizations deliver, however, it often ignores the internal processes, structures, and cultures that make nonprofits effective as mediators of change and contributors to community well-being. Within other disciplines (e.g., management, sociology) the concept of organizational learning (Argyris, 1993; Pawlowsky, 2001) and related ideas, such as situated learning (Gherardi, 
Nicolini, \& Odella, 1998; Lave \& Wenger, 1991) and communities of practice (Brown \& Duguid, 1991; Wenger \& Snyder, 2000), have been widely studied but have received little attention within community psychology. Although much of the research related to organizational learning has been in the context of large, for-profit organizations (Fisher \& White, 2000), organizational learning theory offers an alternative model of adaptation and change that is more consistent with the values and social mission of nonprofit organizations than traditional business models of organizational effectiveness (Addleson, 2000).

\section{INDIVIDUAL AND GROUP LEARNING IN THE CONTEXT OF ORGANIZATIONAL CHANGE}

Learning organization theory views individual and organizational learning as interdependent, which is in keeping with community psychology's ecological approach to understanding community phenomena. The relationship between individual and organizational learning has been widely researched and written about in two separate, but related, literatures. The first, focused on organizational learning theory, is primarily concerned with how organizations learn. The second, learning organization theory, asks the questions how should organizations learn, what are the practices that characterize effective and adaptive organizations, and what are the processes that facilitate learning in organizations? (Easterby-Smith, Snell, \& Gherardi, 1998). Although there is much that divides the two literatures (see Tsang, 1997), much of what we know about learning organization characteristics and best practices has been generated by organizational learning research.

Cyert and March's 1963 publication of The Behavior Theory of the Firm marks the clear beginning of the organizational learning field; however, the field's exponential growth has led to a body of research that resists being neatly placed in subfields or defined categories (Pawlowsky, 2001). Nonetheless, two explicit currents in the organizational learning literature have emerged: the individual/cognitive and the social/cultural (Easterby-Smith et al., 1998). The individual/cognitive perspective, grounded in the disciplines of psychology and managerial science, takes theories of individual learning and information processing as the basis for understanding organizational learning (Pawlowsky). March (Cyert \& March; Levitt \& March, 1988), and later, Argyris and Schon (1996) are in this tradition (Easterby-Smith et al.; Pawlowsky). March's contributions are associated with an information-processing lens, in which learning is portrayed as a "cyclical process that links individual belief to individual action to organizational action to environmental response and back to individual belief" (Friedman, 2001, p. 398). Argyris and Schon, on the other hand, see organizational learning as originating when a member of the organization acts to resolve a problematic situation. In this process, the person experiences a discrepancy between the actual result of their actions and what he or she thought would happen. This event then triggers a cycle of reflection and action that ultimately leads to a revision in his or her perception of the organization and a change in activities in order to resolve the discrepancy between expected and real outcomes of action. Argyris and Schon argue that

[I]n order to become organizational, the learning that results from organizational inquiry must become embedded in the images of organization held in its members' minds and/or in the epistemological artifacts of (maps, memories, 
and programs) embedded in the organizational environment. (p. 16, cited in Friedman, p. 399)

An ongoing and important debate in the literature concerns whether organizational learning is incremental or radical (i.e., first- or second-order change). Cyert and March (1963) originally argued that organizations learn incrementally, and that this learning is reflected through adjustments that are made to organizational routines. Based on the work of Bateson (1972), Argyris and Schon (1996) have broadened this perspective on learning by claiming that incremental learning often undermines an organization's capacity to change because it is essentially a reactive form of learning. As a result, an organization might adjust making small changes in response to feedback from the external environment, but it would not change its underlying structure, values, or objectives. Radical learning, or what we refer to as transformational learning, by contrast, is an organization's capacity to recognize that underlying assumptions about external conditions no longer match the environmental feedback received. It is through the process of critical reflection (Freire, 1998), which can be defined as the process of holding out one's thoughts and actions for inspection and questioning the fundamental assumptions upon which they are based, that new insights, interpretations, and frames of reference emerge. Miner and Mezias (1996) assert that the incremental versus radical debate has evolved into a more complex picture in which organizations are now seen to need both kinds of learning in order to be successful.

In contrast to the individual/cognitive perspective, the social/cultural perspective, represented by sociology and anthropology, views the group as the central unit of analysis. Cook and Yanow (1993), for example, see organizational learning as embedded in culture, but in a way that is complementary to the individual/cognitive perspective (Easterby-Smith et al., 1998). Within this tradition, the work of Argyris (1993), Schein (2004), and others is in keeping with the definition of "organizational learning as a change in defensive routines within organizations, as the development of an organizational learning culture, or as both" (Pawlowsky, 2001, p. 72). Schein, for example, has identified 10 characteristics of a learning culture and has framed the position of learning leader as culture manager. Argyris's (1994) theory exploring the role of defensiveness as a barrier to organizational learning also speaks to the need for creating an organizational culture that minimizes defensive behavior and actively supports open, honest communication that focuses on learning.

Organizational learning viewed through these two distinct theoretical currentsindividual/cognitive and social/cultural—has many limitations and inevitably leads to oversimplification (Easterby-Smith et al., 1998). Cyert and March's (1963) work, for instance, clearly comes out of an individual-level cognitive tradition but also focuses on the group level of analysis. Argyris's early work with Schon (1996) fits squarely within the individual/cognitive tradition, yet his later work on defensive routines (Argyris, 1997) is concerned with the larger issues of developing an organizational culture conducive to learning. Despite these ambiguities, framing these two perspectives as distinct does offer a useful way of understanding some of the disciplinary influences on the field of organizational learning and how these inform the construct of the learning organization.

If organizational learning signifies the process, then the learning organization represents the ideal or goal. Learning organization theories highlight the interdependent relationship between individual and organizational learning viewing the individual as 
the agent of organizational learning and change. These theories also point to the role that organizational culture, structures, and systems play in facilitating or blocking organizational learning. Senge (1990) defined a learning organization as one:

that is continually expanding its capacity to create its future. For such an organization, it is not enough merely to survive. "Survival learning" or what is more often termed "adaptive learning" is important-indeed it is necessary. But for a learning organization, "adaptive learning" must be joined by "generative learning," learning that enhances our capacity to create. (p. 14)

Senge's definition bridges several of the debates particularly within the individual cognitive tradition. Senge sees the importance of the incremental learning processes associated with the behavior theory of the organization tradition, but like Schon and Argyris, he calls for a qualitative shift in perception and thinking in which individuals understand the organization as a system and experience their work as part of that system. Finally, Senge identifies team learning as the bridge between individual and organizational learning, stating "This is 'where the rubber meets the road'; unless teams can learn, the organization cannot learn" (p. 10).

Marsick (2000), like Senge, comes out of an individual/cognitive learning tradition focusing on adult learning theory. She underscores the interdependent, yet distinct, characteristics of individual and organizational learning, cautioning that:

Systems learning cannot occur unless the system as a whole is adequately prepared to absorb and use this learning so that it becomes shared, easily accessed, and productively employed in the service of the systems agreed upon vision. (p. 10)

Marsick and her colleagues have made several contributions to the field, including a developmental model of team learning based on empirical research findings. In this model, Kasl, Marsick, and Denchant (1997) describe three distinct modes of team learning-fragmented, pooled, and synergistic - that progressively move from an individual orientation toward learning to one in which team members begin to mutually generate new knowledge. Marsick recognizes the bridging role groups and teams have in facilitating individual and organizational learning. Marsick and her colleagues have also been instrumental in synthesizing the learning organization literature through a descriptive model of the major organizational characteristics, management practices, and individual and team-level foci for creating a learning organization, which we have summarized in Table 1.

In sum, a learning organization is a best case or best practice: an organization that has both the infrastructure and the culture necessary to support the process of organizational learning. The individual is seen as an active agent and acts to intervene in organizational processes. Organizational learning, by contrast, refers to the capacity of an organization to transform its underlying structures, cultural values, and objectives in response to, or in anticipation of, changing environmental demands (Argyris \& Schon, 1996). Hence, a learning organization depends on openness to new ideas and change at both the individual and organizational levels. But what of community change? 
Table 1. Learning Organization Characteristics, Practices, and Foci (based on Marsick, 2000)

\begin{tabular}{|c|c|c|}
\hline $\begin{array}{l}\text { Learning Organization } \\
\quad \text { Characteristics }\end{array}$ & $\begin{array}{c}\text { Learning Organization } \\
\text { Core Practices (Watkins } \mathcal{E} \\
\text { Marsick, 1993) }\end{array}$ & $\begin{array}{c}\text { Foci for Enhancing } \\
\text { Organizational Learning }\end{array}$ \\
\hline Systems thinking capacity & $\begin{array}{c}\text { Providing strategic } \\
\text { leadership for learning } \\
\text { Connecting the organization } \\
\text { to its environment }\end{array}$ & $\begin{array}{l}\text { Critical reflection: } \\
\text { "provide people and } \\
\text { systems with the ability to } \\
\text { enhance what is an } \\
\text { otherwise tacit, experiential }\end{array}$ \\
\hline $\begin{array}{l}\text { Continuous learning } \\
\text { at the systems level }\end{array}$ & $\begin{array}{l}\text { Creating continuous } \\
\text { learning opportunities }\end{array}$ & learning process" (p. 11) \\
\hline $\begin{array}{l}\text { Greater participation and } \\
\text { accountability by a larger } \\
\text { percentage of employees }\end{array}$ & $\begin{array}{l}\text { Encouraging collaboration } \\
\text { and team learning } \\
\text { Empowering people } \\
\text { toward a collective vision }\end{array}$ & $\begin{array}{l}\text { Collaboration: "can } \\
\text { provide avenues for } \\
\text { building joint knowledge" } \\
\text { (p. 11) }\end{array}$ \\
\hline $\begin{array}{l}\text { Culture and structure } \\
\text { of rapid communication } \\
\text { and learning } \\
\text { Knowledge generation } \\
\text { and sharing }\end{array}$ & $\begin{array}{l}\text { Promoting inquiry } \\
\text { and dialogue } \\
\text { Creating systems to } \\
\text { capture and } \\
\text { share learning }\end{array}$ & $\begin{array}{l}\text { Communication: } \\
\text { "provides for feedback } \\
\text { loops across the system" } \\
\text { (p. 12) }\end{array}$ \\
\hline
\end{tabular}

\section{ORGANIZATIONAL LEARNING IN THE CONTEXT OF COMMUNITY CHANGE: ASSUMPTIONS AND CHALLENGES}

Despite the appeal of the organizational learning concept, both its utility in varied community contexts and its limitations need further exploration. Another central principle of organizational learning is worker participation and empowerment. The emphasis on organization-wide participation and choice within this literature is similar to the role empowerment theory has played in community organizational contexts (Peterson \& Zimmerman, 2004; Speer \& Peterson, 2000), yet some argue that the role of power and empowerment deserves more attention from organizational learning researchers (Mojab \& Gorman, 2003) and that the cursory treatment of power and politics illustrates the shortcoming of the learning organization model as reflecting an ideal rather than organizational realities (Rhodes, 2002). Others (Coopey, 1995; Snell \& Chak, 1998) raise the critical question of "learning and empowerment for whom?" suggesting that only the upper echelons of an organization have access to opportunities to engage in organizational learning. A related criticism concerns the fact that much of the research has been done in organizational contexts with highly skilled workers where menial or production tasks have been outsourced (Mojab \& Gorman, 2003).

Perhaps the greatest limitations of the management-oriented learning organization literature are that the extraorganizational context to which it attends is very different from the community context in at least two important ways. First, organizational theorists tend to assume that the same organizational goals, structures, and processes apply across very different organizational contexts. In business organizations, profit may be a goal that can be generalized across contexts; however, there is a need to understand how these assumptions might hold up in smaller community-based nonprofit organizations, many of which rely heavily on volunteer members to carry out the work of the organization 
(Herman \& Renz, 1999). Second, connecting the organization to its environment is a learning organization principle, but for it to be relevant to community psychology, it is important to identify what particular aspects of the environment are relevant to what kinds of organizations. Clearly, aspects of the sociocultural, economic, and physical environment are important (Christens \& Perkins, in press). But the local-to-global political context is especially important to an organization's ability to address root causes of problems and, unfortunately, the organizational learning literature's avoidance of internal politics mentioned above is also true of extraorganizational power dynamics.

A broader assumption that much of the above literature makes is that transformational change is an ideal goal. This is clearly a widely held value in community psychology (Prilleltensky, in press), but we are not arguing that incremental change has no place. Individuals, organizations, and communities need stability as much as they need change (Brown \& Perkins, 1992). Ameliorative approaches provide a vital safety net of community services. Incremental change can lead to stable, evolutionary organizational and community development. As a society, however, we devote exponentially more organizational resources to ameliorative change, particularly at the individual level (i.e., medical model interventions and other direct services), than we devote to transformational change at the individual, organizational, and community levels combined. And although it is true that larger social, political, and economic forces may join the sheer size and complexity of both institutional systems and social problems to preserve the status quo and make change of any kind difficult, those are the very same reasons why multilevel second-order change is such an important, if rarely attempted and even more rarely achieved, goal. We are not imposing this as a necessary goal for all organizations, but we have chosen to study organizations that have adopted transformative change as a goal at one or more levels.

Thus, despite its limitations, we believe learning organization theory, which explicitly addresses multilevel change in human communication, knowledge, and decision-making systems, can make a contribution to community-based nonprofit and volunteer organizations and inform community psychologists' efforts to help transform such organizations and engage in systemic community change.

\section{MODEL OF THREE LEVELS AND TWO ORDERS OF LEARNING, DEVELOPMENT, AND CHANGE IN ORGANIZATIONS}

Our research questions at the beginning of the project included: How do nonprofit organizations serve as contexts for individual learning and development? What are the key organizational learning characteristics of successful community-based nonprofits? How do nonprofit organizations become effective agents of community change?

This led us to seek a conceptual framework that could represent first- and secondorder change at the individual, organizational, and community levels. ${ }^{1}$ Based on the above literature, we further argue that both learning and empowerment-related structures and processes may be critical to second-order change at each level. Development is the context at each level, and development may be either incremental or transformative. Organizational learning theorists think of empowerment as part of, or a mechanism for, learning. We prefer to think of empowerment and learning as partially overlapping at each level-they are mutually reinforcing, but there are also independent aspects of each as their objects differ (Francis Bacon notwithstanding): power versus knowledge. 
We thus propose a three-dimensional spatial framework (see Figure 1) to help organizational researchers and administrators identify the ideal goal of transformational change at all three levels (represented by the arrow in Figure 1) and diagnose where a given organization is currently and where it may decide to target more activity or resources to maximize change at all three levels. We hypothesize that change at each level is, at least partly, dependent on change at lower levels; that is, that second-order community change requires empowered organizations addressing problems at a systemic level and that transformative organizational change requires members who have moved beyond understanding just their own roles to a larger awareness of the entire organization and the power dynamics both within and external to the organization. The key diagnostic variables for analyzing community organizations in terms of their transformative versus ameliorative structures and processes at each level are: (a) individual learning, skill, and political consciousness development; (b) organizational learning and development; and (c) community second-order (transformative) as opposed to first-order (ameliorative) change in systemic power relationships and material conditions. These variables are further discussed below and in each case study. By employing an ecological framework and studying the relationship among individual-, organizational-, and community-level phenomena, we can begin to examine differences across levels and organizational contexts in what leads to first- and second-order change.

We will illustrate the proposed model by analyzing three case study organizations, locating their position in the cube, and exploring the ways in which each of their positions affects their capacity to engage effectively in second-order change. To diagnose whether an organization is transformative at the individual level, we ask questions such as: What is the substance of individual-level learning in the organization? Is it focused more on narrowly defined roles and tasks of the participant within the organization and just at their current level and job, or does it challenge participants to develop broader skills and understand political issues, structures, and processes of the organization and community?

To diagnose whether an organization is a "learning organization" and transformative at that level, we ask questions such as: Are curiosity, creativity, systems thinking, critical reflection, and dialogue encouraged in the organization? Is there evidence of continuous learning at the systems level? Are collaboration and team learning processes encouraged? Are members at all levels of the organization empowered, given a voice, and encouraged to participate fully and actively in decision making? Are there real efforts to develop a collective vision? Do communication and feedback loops function quickly and effectively across the entire system? Few, if any, organizations can live up to all of those criteria, but they are some of the dimensions that help to diagnose whether an organization is geared more toward homeostasis (system maintenance) or organization development (system change; Marsick, 2000).

To understand whether an organization is transformative at the community level, we ask questions such as: Do the mission, strategies, and tactics of the organization address structural root causes of community problems? Do they deal with issues of social, political, and economic oppression, liberation, and justice? Does the organization involve significant and representative numbers of community members in important decisions and operations and in active and meaningful ways? Often, the public presentation (mission) of an organization may be transformative while the operational strategies and tactics are really more incremental and ameliorative, or focused more on individual change than community or societal change. 


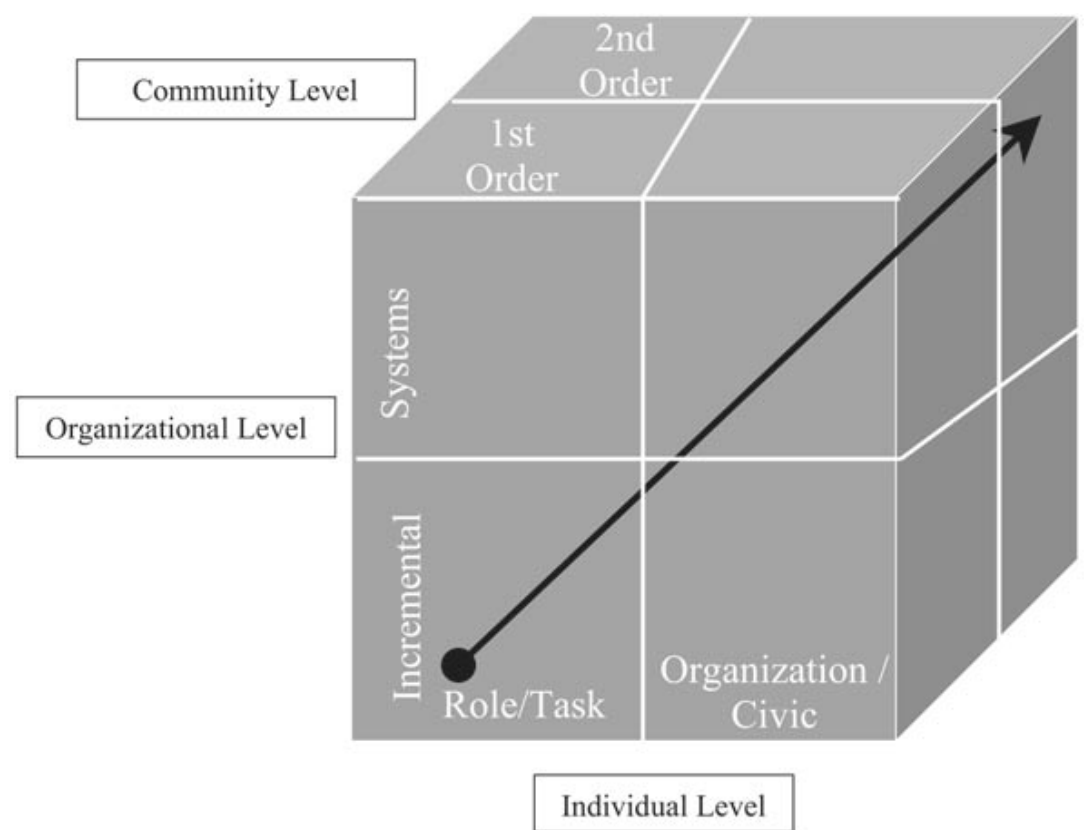

Figure 1. A three-dimensional model of levels and orders of learning, development, and change in organizations.

\section{PROJECT BACKGROUND AND METHODS}

The present case studies are part of an exploratory project using mixed methods to study community organizations as contexts for multilevel learning, development, and change. Faculty, graduate students, three undergraduate service-learning classes, and a community advisory board collaborated on the planning and data collection in three separate phases over a two-year period (2002-2004). The setting for this study is a mid-sized, Southern U.S. city.

Phase One of this project began with the compilation, from multiple sources, of a comprehensive database of all 2,361 community-based, nonprofit human service, volunteer, and member organizations throughout the city. Ten types of organizations were identified based on the setting, population, or need served: social/family/senior services, youth/recreational, faith-based, school-based, neighborhood, immigrant/ international, environmental/community development, political/advocacy, labor, and philanthropic/arts/cultural. Many organizations are of multiple types.

Phase Two of the project was a brief telephone survey of 270 of those organizations, in which we measured such organizational characteristics as staff/membership size, use of volunteers, the nature and extent of their activity, organizational type and goals, and what learning processes are being employed to achieve them. A content analysis of the open-ended question about the nature of volunteer, staff, and organizational learning goals was conducted, and five categories of learning goals emerged: goals related to (a) 
skills, task, or attitudes; (b) the organization's content area or mission; (c) the organization's operation or functioning; (d) civic or political learning; and (e) lifelong learning.

The present, preliminary qualitative analyses are from Phase Three of the study, in which the results of the survey and recommendations from the project's community advisory board were then used to select 16 organizations, stratified by organizational type, for in-depth, qualitative case studies. Case studies are based on field notes of brief participant observations and systematic content analysis of in-depth, semistructured interviews of directors, staff, board members, and volunteers of each organization.

We used three criteria for case study organization selection: (a) inclusion of at least one organization representative of all but one of the 10 identified types of nonprofit organizations (arts/cultural/philanthropic organizations were seen as less oriented toward community change, a main focus of the larger project); (b) inclusion of at least one exemplar organization from each category that showed potential characteristics of a learning organization; and (c) where possible, to maximize diversity of organizations within types (e.g., both a politically progressive faith-based coalition as well as a church that had been a member of the conservative Christian Coalition). Exemplars were recognized as those who noted in the survey having learning goals for volunteers or were known by community advisory board members as being high functioning and as valuing volunteer learning.

In addition to field notes based on student participant observations, we interviewed 38 individuals across the 16 selected organizations using a semistructured format. The interview protocol (available on request) included a series of open-ended questions about organizational goals, efforts to inform or influence a government official or local business about an issue, organizational crises or critical needs, and new programs or activities. Each of these questions was followed by a series of probes inquiring about specific examples, problem-solving and decision-making processes, action steps and methods, and volunteer involvement.

For each organization, up to four participants (no more than two in any given role of leader, staff, volunteer, or board member) were interviewed. These interviews were tape recorded, transcribed, and entered into NVIVO, a qualitative software program, for coding. Field notes from students participating in the study both as interviewers and service learners were also collected and coded. Coding occurred in three stages. In step one, the seven collaborators on the project used an open coding process to establish emergent themes and categories. We organized categories based on a framework developed by Peterson and Zimmerman (2004) of intra-, inter-, and extraorganizational themes. Within these themes, we established microcategories. To establish intercoder reliability, we engaged in a process in which coders rated interviews independently and then as a group. Finally, each of the remaining interviews was assigned to two coders.

We have selected 3 of the 16 organizations to present as contrasting exemplary case studies: (a) a participatory neighborhood and downtown planning organization, (b) a grassroots faith-based social action coalition, and (c) a large community-based human service agency.

\section{THREE ORGANIZATIONAL CASE STUDIES}

\section{Case 1: City Space Collaborative Planning Organization}

City Space ${ }^{2}$ is an organization that is engaged in both transformative and incremental learning at the individual level, incremental learning at the organizational level, and 
some second-order community change. City Space is a nonprofit environmental design center composed primarily of architects and urban planners whose mission is to "elevate the quality of (the city's) built environment and to promote public participation in the creation of a more beautiful and functional city for all." To achieve these ends, City Space's initiatives involve education, consultation on civic and community development projects, public dialogue through open forums, and research on the impacts of design and development. This four-year-old organization was created by a group of architects, who serve as board of directors, with the idea that such a center would help attract investment and development into the city, thus creating more work for downtown firms. However, since its inception, it has evolved into an organization with a strong focus on community improvement and participation, while still operating under the constraints of a for-profit-sector board of directors. The most recent major program involved developing a comprehensive, community-based vision for the future development of the entire central business district of the city, involving the input of more than 800 community volunteers from over 10 different inner-ring neighborhoods and downtown.

At the individual level, the learning that occurs within City Space has an incremental component in relation to roles and tasks, but also encompasses a broader systems perspective that includes transformative civic learning (e.g., monthly forums and ongoing projects help staff and volunteers learn about the key players and forces that affect city and neighborhood development). The paid staff of City Space is very small, consisting of a handful of architects and planners who conduct operations on a day-to-day basis, making the use of volunteers essential to the survival of the organization. Voluntary board members, interns, and community members-at-large contribute in numerous, mostly prescribed, ways. City Space possesses a structure in which functions are inherent within different organizational roles. Although tasks and role functions are not dictated, they are inherent in the organization's structure. Interns are usually hired as research interns or design interns, with roles in both cases predetermined. Office and design interns perform tasks specific to the position and current projects. The majority of learning that occurs is role based and, therefore, necessarily incremental. Interns are not typically involved in organizational decision-making processes but are encouraged informally to learn about the organization's mission and civic design issues, as well as the structures and systems that affect them because the two are intertwined. This represents the secondorder learning component; however, such learning is self-directed and informal as opposed to formally dictated, as in the case of task-related learning. A paid staff member further expands on this in describing the systems-learning process for voluntary staff:

... there's no structure for that. I mean, not even for my job. . . There's no orientation or ... presentation or expectation of what you're supposed to be doing. ... I mean they'll teach stuff along the way as you need to learn it, but it's not like, okay you're here to learn this so let me start teaching you.

In the case of community volunteers, roles can be specific to organizational function, such as participation on a committee, or to a given project, such as the comprehensive community vision plan. In the case of the former, learning is task specific and incremental, but in the case of the latter, it is both incremental and systems oriented. The learning as a committee member is task specific, requiring a specific body of knowledge, but the simultaneous learning as a program participant is more civic and transformative in nature. An individual in a directorial role explains this dichotomy within the voluntary committee role: 
... It's actually part of the education process. If we can get 15 important people to spend one hour a month looking at the issues we have to deal with, and they take that back to their offices, the state architect takes it back to his office, the head of the ... science museum takes it back to his ... place, a lawyer with First Bank takes it back to his place ... . that's part of the education process. And these are the same people that sit on other committees and stuff around here. So those volunteers are very important.

The voluntary committee member performs a specific task, and at the same time becomes involved in the educational process of the organization in hopes that the knowledge imparted by the process will eventually infiltrate different areas of the private and public sector, thus helping to facilitate transformative civic change. The overarching goal of facilitating community participation in the development process is itself transformative in nature, and necessitates understanding about structures that have affected design and inhibited participation in the past. Consequently, dialogue concerning transformative change is inherent to internal organizational processes and within forums, educational programs, and collaborative projects with the community at large. The volunteer plays both a functional role to the organization where learning is incremental, and a participant role as a recipient of the organization's initiatives, where learning is transformative.

Learning and change at the organizational level is primarily incremental, due to gaps in communication systems, but there are nonetheless some characteristics that are consistent with a learning organization, such as structures to capture learning at different levels. The organization's focus is primarily the implementation of programs and goals, in other words, on production. Learning at this level is primarily reactive, as there is a lack of critical reflection about structures and organizational processes unless a problem or crisis occurs. In some cases, staff members take it upon themselves to ameliorate issues without confronting the systemic nature of the problem in the organization. ${ }^{3}$ A staff member described this process:

We delegate the responsibilities amongst the staff [without management input]. ... We go into a room and ... complain for about an hour and then we figure out what to do.... It's usually [just] the staff, and then the director is filled in at some point. ...

The underlying structural problem, in this case, is never addressed due to the gap in both communication and power between staff and management. Instead, it is only temporarily ameliorated. Furthermore, there exists a communication gap and vision discrepancy between the office staff, including those in directorial positions, and the board of directors. Since City Space was originally conceived as a catalyst for architectural business, the board is wary of projects that could potentially take work away from downtown firms, which sometimes conflicts with the community-based vision of the staff and volunteers. Hence, the board and staff communicate infrequently, and typically just when the board tries to limit the projects that the staff takes on. These communication gaps illustrate that learning at the organizational level is incremental in nature, lacking an understanding of organizational systems necessary for transformative change. A staff member described an episode that illustrates such a gap:

... For instance, there was a group that came in and asked us to do some work.

We put it through and when it got there the committee looked at it and said, no 
... these people have money, they can hire someone to do this work for them. They should hire someone to do this work for them. This is not something we should be spending our time on.

In this example, the staff wanted to provide technical assistance to a community group, but the board felt the prospective clients should hire a firm in the private sector instead, illustrating a gap in organizational vision. This example is indicative of regular discrepancies of vision between staff and board, and also represents incremental organizational learning. Neither staff nor board address this as a systemic issue and thus do not practice transformative organizational learning. Although communication gaps exist between staff and management, and staff and board members, there are structures in place to capture and learn from volunteer knowledge. Volunteer committee members contribute knowledge to the organization that is then used to evaluate and modify organizational direction and initiative. Likewise, community knowledge is also integrated into the organization in a bottom-up fashion through the public forum where creativity and new ideas that could potentially change the course of the organization are encouraged.

Although learning and change at the organizational level is primarily incremental, these last examples illustrate the potential for City Space to engage in transformative organizational learning on a more consistent basis.

At the community level, City Space is mainly engaged in first-order change-primarily in the form of improved neighborhood planning and site-level design-but has some potential for second-order change through its neighborhood and city-wide participatory planning initiatives. The general organizational goal of increasing the quality of the built environment contains an inherently ameliorative component. Part of the work the organization engages in translates into physical changes in specific areas or communities without any systemic change taking place. However, the fact that one of its specific goals is to increase community participation in the civic sphere creates potential for transformative-second-order-change. Generating a community-based plan for future development is an attempt to transform the top-down fashion in which development decisions are usually made. This attempt at planning with communities as opposed to planning for communities could set a precedent for further participation in the development process at a structural level.

The educational programs and public forums run by the organization attempt to raise awareness about all aspects of urban design, including forces that affect social and economic oppression. This public education process has the potential to facilitate transformative change if it was coupled with community organizing and action efforts. Its immediate impact, however, is to educate mainly those who already possess expert knowledge, as community members without a professional association to the design and development process are conspicuously underrepresented at forums and education classes. Therefore, second-order change remains elusive to City Space, particularly at the organizational level, and it is still more potential than reality at the individual and community levels as well.

\section{Case 2: Community Faith Network}

Our analysis suggests that Community Faith Network (CFN) provides opportunities for transformative learning and change at the individual and community levels, but is more incremental than systemic in its allowance of change at the organizational level. As a 
broad-based community organization that consists of churches and other community groups, whose mission reflects how "people of faith and power come together to improve the community," the organization's goal is to work on behalf of the community's interests by developing a network of citizen power in the city. As one CFN leader put it, "Our big, big goals are equity and justice for our community. That's kind of our code words, as far as I'm concerned, equity and justice." Through its work, CFN provides an outlet for addressing community-level issues, particularly on behalf of persons otherwise excluded from more traditional power-based decision-making arenas, including politics and the local marketplace.

Officially founded in 1993, CFN is composed of approximately 70 member congregations and other community groups. As an affiliate of a larger national network of likeminded community organizations, CFN draws heavily on the history and guiding principles of its parent organization. This includes intensive efforts at localized personto-person conversation and consciousness raising, information gathering, direct action campaigns, and occasional public accountability sessions with official power holders and brokers.

... the fact is we're trying to address what I call systemic issues. So you can never achieve those by getting one person to change their mind or one person to do right, or one group saying okay you're right, we're going to make that change. It always involves an array of people and organizations that we're trying to deal with. So to me that's sort of the hardest thing we have to do is to learn how to do that. (CFN volunteer)

Learning in the Community Faith Network can be transformative for its volunteers who, excluding a small handful of paid staff, constitute the organization's participants and core governing body. As a member of an affiliated organization, almost anyone can get involved in CFN. Volunteers have opportunities to attend any of the different types of meetings held by the organization: research, leadership, and strategy meetings, and meetings with public officials or agencies. Meetings with public officials or agencies are usually preceded by planning meetings, and any member who shows up to these planning meetings can volunteer for, or be asked to do, something. Most become involved either because they're aware of the positive reputation of CFN or because they are concerned about a particular local issue. Individuals can grow and learn through their work with CFN in traditional organizational roles and tasks, as well as through the opportunity to volunteer for a wide variety of tasks, learn about the general process of community organizing, and deepen their understanding on local issues of inequity in the community in areas such as schools, local stores, and their neighborhoods.

In recent years, CFN has worked to improve a number of issues in the community, for example, its work in schools, such as addressing the inequity of physical structures and maintenance in schools, building a "parent power" organization, and working to develop reading and writing standards for parents to use with their children. Although some of its activities appear focused on first-order change, through the process of surveying its membership for issues of concern and research it engages in winnable second-order (transformative) community change by advocating for policy and structural changes.

So you know the business community is able to get things done by the way it can influence politics. And then the politicians put the laws into place, set the policies, and so that gets something done. And CFN is ringing up the people as 
another power player and making instead of a bilateral thing it makes it triangle. And so it only makes sense that we need to be approaching that business community to complete the connections in the triangle. It's clear as can be. (a CFN religious leader)

Although CFN is moderately transformative at the individual and community levels, organizationally it is more incremental or ameliorative in its change process, and the organization itself is less reflective about its procedure and operations in order to make change. This is largely because the organizational focus is on developing new leaders and effecting community change. Curiosity, critical reflection, dialogue, and team learning are encouraged in the organization, and at every level members are encouraged to participate fully in decision making. By these accounts, CFN fits the definition of a learning organization. Underlying these processes, however, is a structure that is fairly rigid in its adherence to the national network's organizing model and somewhat hierarchical and undemocratic in its decision-making process.

So pretty much we try to go by the model that we have and what's in place. I can assure you it doesn't always work perfectly and that people get ticked off or think we're going too much this way or that way. I think one of the sort of subterranean things going on right now is . . . that people think ... that we're not quite democratic enough all the time ... that the leadership team or some leaders seem a little too autonomous or that they're sort of giving a little too strong of input. (CFN leader)

Related to the problem of leadership and lack of democracy is CFN's inconsistently employed and temporary lack of nationally trained and locally paid organizers. While CFN continues to enjoy a positive reputation in the community, one volunteer notes "probably as near crisis that I've experienced so far is just the current lack of (organizing) leadership. ... and we don't have a lead person right now to invite." Although not readily apparent, this situation has caused the organization to stray from the way it normally does its work in an effort to maintain its image. Members of the organization are being stretched to fill more roles as the number of actively involved individuals and organizations are waning. Additionally, financial resources have decreased, limiting staff resources.

There is reason to be hopeful about the resolution of this crisis, and that is the culture of the organization itself. CFN trains its members to ask tough questions and constantly, sometimes painfully, reflect on the work being done. It is now beginning to apply that same process to itself in order to address the problems and is surfacing issues related to the top-down structure of decision making. Whether the resolution of this crisis will lead to changes in the organization's structure and processes is yet unknown. Doing so would cause us to reevaluate CFN's place in the model (see Figure 2).

\section{Case 3: St. Daniel's Community Organization}

St. Daniel's Community Organization has, for over 90 years, served the working poor in its neighborhood. With a very clear sense of identity and mission, it stands out as an example of a highly complex organization that has gone through a radical transformation within the past decade, increasing its organizational capacity for learning and 
change. Within the context of our framework, St. Daniel's exemplifies a nonprofit that is transformative at the individual and organizational level, but not engaged in secondorder community change. Opportunities for individual learning have increased as community members, volunteers, and staff work together at all levels to address community needs. At the community level, however, the organization views its mission as ameliorating conditions for poor residents rather than addressing the root causes underlying those conditions. This story illustrates both the interdependence of individual and organizational learning as well as the salience of person and environmental factors that contribute to learning and transformation.

The organizational event, which, by all accounts, marked the turning point for St. Daniel's and triggered a series of changes resulting in a qualitative shift in the organization's functioning, was the untimely death of the executive director. Known as the "ultimate volunteer," the executive director showed little capacity to build and manage organizational resources. The successor, by comparison, was described as a leader with the capacity to build and manage an organizational system that maximizes effectiveness. Under the old leadership, the organization had in place some of the cultural characteristics necessary for organizational learning but did not have in place the structures (e.g., roles and positions) or leadership necessary to transform itself into a learning organization. Under the new leadership, the data suggest that St. Daniel's has integrated a wellestablished culture of participation and learning with organizational learning practices. The capacity of the organization to provide opportunities for transformational learning at both the individual and organizational levels can be partially linked to the development of a complex and integrated role structure, a long history of a learning culture, and a highly developed network of partners and collaborators.

The data suggest that St. Daniel's has developed a highly integrated organizational structure in which roles are strategically differentiated for staff, volunteers, and community members but often overlapping. The integration of members in all aspects of the organization increases individual opportunities for learning and enhances organizational capacity by inviting input into decisions from stakeholders with different perspectives. A St. Daniel's staff member illustrates this point in her description of the process they used to decide whether to keep a particular program operating:

[W]e had started off with lots of conversations with our board [and a] task force made up of leaders in the community. And we also had the family resource center advisory council that was involved in the decision making, which is made up of people that live in the neighborhood and our council person and different people. So we had a lot of bodies that were really studying it to see what the viability is to make sure.

This story exemplifies how critical reflection, inquiry, dialogue, and widespread participation are embedded into the organization's practices, enhancing opportunities for individual learning and effective organizational decision making.

Another aspect of the structural integration of roles at multiple levels can be seen in examples of individuals filling multiple roles in the organization. For example, one way in which the organization serves the community is to hire staff from the community. Community members also serve on study committees that are specifically engaged in identifying community needs. The associate director began her affiliation with St. Daniel's as a volunteer tutor in the reading program. Professional staff and board members often serve in additional volunteer roles. One board member explains: 
... the only way to really be a board member that can be totally effective is you've got to understand what the business is. You've got to go out there and deliver meals, or you've got to participate in the day care program or the food bank program.

This overlap of roles allows staff, volunteers, and community members to participate in shared experiences and keeps them connected to the mission of the organization and the pulse of the community. It also gives them opportunities to develop broader skills, to learn about the perspectives of others, and to better understand the structures and processes of the organization and community.

St Daniel's very long history of survival is marked by repeated examples of a learning culture linked with the organization's mission. According to each of the participants, the mission to serve the needs of local community residents has remained constant throughout, but the programs have shifted and changed over time. The expectation of change has been integrated into organizational life historically in the form of a learning culture and exemplifies key characteristics of a learning organization, the capacity to shift to changes in the environment. A volunteer who has been involved with St. Daniel's since 1949 explains how this translated into practice during the 1960s:

... the board of St. Daniel's made the Settlement Guild sort of an arm of the board to find out what the needs were and what we might do to help. So we did a survey of the neighborhood which indicated that day care was the prime need. ... And so the way we met that need was with the thrift shop, trying to find a project that was ongoing, that it would serve the neighborhood. . . .

This is but one example of how the organization has a history of identifying and addressing community needs in collaboration with community members. As the associate director explains:

this agency has always been of the mindset that we are of the community, that we weren't a separate entity ... that we weren't a service provider, per se. [We have] that mindset of being a partner with the community and assisting them and empowering them to even meet their needs themselves.

St. Daniel's organizational learning culture has served as the foundation for many of the recent changes in which participation and a shared mission have assisted new leadership in building structures (e.g., roles) and a vision for future development. A board member and long-time volunteer framed it this way:

Now you've got the same culture that's doing it in a more sophisticated way, more of a business model with a planning process and so on and so forth. But to me the culture is the part of why you don't lose sight of why you're there to begin with.

St. Daniel's has also increased its capacity by expanding its network of strategic alliances. In doing so, it is engaging in the learning organization practice of connecting the organization to its environment. These alliances also serve as learning opportunities for individuals in the organization. The data illustrate the multiple ways in which St. Daniel's collaborates with influential individuals, government officials, local and government agencies, neighborhood groups, local social service agencies, volunteer groups, faith-based organizations, corporate partners, and funding agencies. These alliances provide 
a broad base of financial and volunteer support, as well as expertise, and serves as a major learning resource for the organization. Beyond financial benefits these partnerships provide, many are seen as essential to carrying out the mission of the organization and are approached strategically, as illustrated by the associate director:

... we bring in partners that are government or ... nonprofit agencies. . . So we have to be that liaison and really educate our families . . . "try it and give us the feedback and let us know . . . if this is not going to meet the community's needs, we'll change." We've ended collaborations with area agencies that have been offering services here because we have gotten feedback from families that "this isn't really meeting my needs" ... I would hate to have a program just for the sake of having a program.

This last comment illustrates the extent to which St. Daniel's has moved from an organization "flying by the seat of its pants" to an organization that very deliberately pursues relationships and partners that are in line with what it perceives to be the interests of its community.

That St. Daniel's will continue to be successful in serving the community residents seems highly likely. Its longstanding relationship with the community, its history of adapting to meet community needs, and the recent changes in its organizational capacity all contribute to a picture of an organization that not only provides a context for individual learning and development of its members, but also can adapt and change in a complex environment. Interestingly, however, its mission, which has served to anchor the organization over time, has also limited its work to largely ameliorative activities. Thus, at the community level, St. Daniel's focuses almost exclusively on first-order change. No evidence surfaced in the data indicating that the organization has ever sought to affect the conditions associated with community problems. Rather, the evidence suggests that treating problems as they arise has been the modus operandi. Although the direction of the organization seems unlikely to change in this regard, the associate director acknowledged her own desire for a greater emphasis on social justice. In her wistful description of community members, her own sense of resignation mirrors that of community members and the organization itself:

I very, very rarely sense any kind of victimization in the words that they choose to use, or when they are describing their situation. I very rarely see that. It's just a matter of fact for them. This is who I am, this is where I came from, and this is my situation, which, in some respects, is almost sad. Sometimes I wish they would see themselves as a little bit of a victim of maybe just society because for them a lot of times getting to a place where we can both kind of see that perspective of it might help me convince them that it's not right and it's not okay that people treat you this way.

\section{Summary: Placing the Cases in the Cube Model}

Figure 2 represents our attempt to locate each of the three organizational cases in the threedimensional framework for individual, organizational, and community change. Each organization has three arrows, each representing a level of change and dimension of the cube. The length of each arrow indicates how transformative the organization is at that level. 


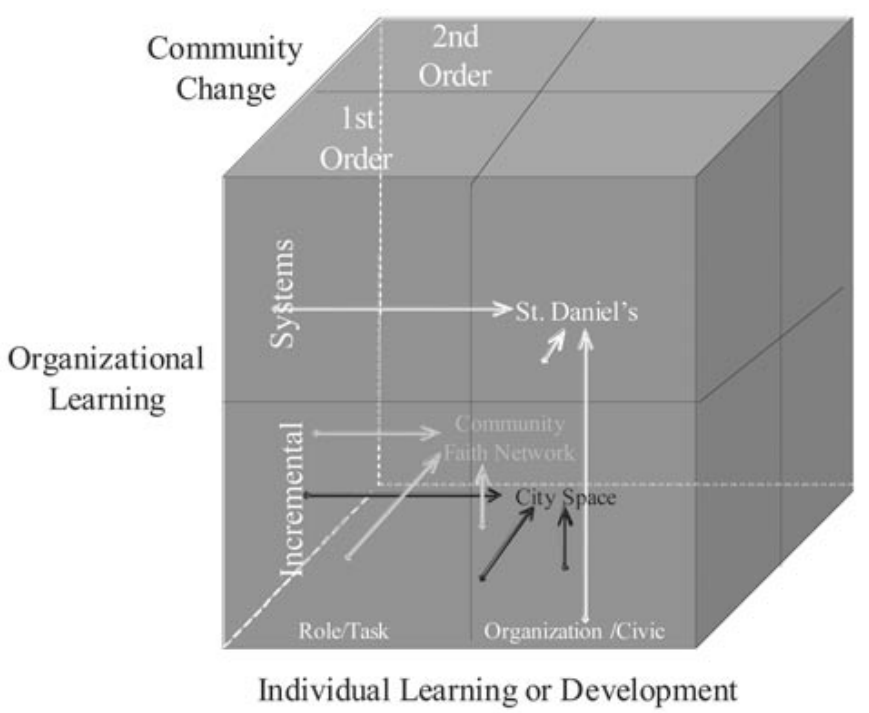

Figure 2. Placement of three organizations in three-dimensional model of organizational change.

City Space is engaged in participatory, community-based neighborhood planning and design and public education. It is an organization that is fairly transformative at the individual level, incremental at the organizational level, and engaged in some modest degree of second-order community change. Similar to City Space, Community Faith Network is moderately transformative at the individual level, incremental at the organizational level, and engaged in "winnable" second-order community change. In contrast, St. Daniel's is an example of a nonprofit that is transformative at the individual and organizational levels, but not engaged in second-order community change. The organization recently underwent a major leadership transition that resulted in a more integrated, complex organizational system. Within this system, opportunities for individual learning have increased as community members, volunteers, and staff work together at all levels to address community needs. At the community level, however, the organization views its mission as ameliorating conditions for poor residents rather than addressing the root causes underlying those conditions. Transformative community change is difficult enough when it is an explicit goal, as with CFN, but it will probably never happen unless more organizations make it a real and central part of their mission.

\section{DISCUSSION}

All three case study organizations were engaged in various forms of incremental learning, at least, which is unsurprising given that they were chosen based, in part, on having learning goals for staff, volunteers, or the organization as a whole. Transformative organizational learning is much less common, and even in these exemplary organizations, in any given organization we found evidence of it at only two levels- the individual and either the organizational or the community level. Second-order change at the community 
level is particularly difficult and only achieved by two of the organizations in fairly modest and circumscribed ways, such as organizing large groups of citizens to pressure city government on one or more particular issues.

In sum, our findings suggest that second-order change becomes progressively more challenging as one moves from the individual and group or team levels to the organizational and community levels. As limited as these examples are, they are consistent with our assumptions that learning that can lead to second-order change must help organizational staff and volunteers to engage in critical analysis of (a) the organization's demonstrated goals and values (not just its mission statement); (b) the power relationships implicit in decision-making practices at all levels (intraorganizational, interorganizational, and in relation to larger power structures in the community and beyond); (c) the interdependent role of participant stakeholders and organizations as part of a complex, community-wide (or larger) system; and (d) how to work toward fundamental change of all the above. It is critical for organizations to develop an understanding of the different networks that are connected to political power and thus have an influence on the distribution of resources. Such systemic learning could help the organization refine strategies and targets of action in pursuit of second-order change.

Our assumption at the outset was that each level of transformative learning, development, and empowerment contributes to transformative change at the other levels. Our interviews and observations provide some support for this. The bigger questions, however, are (a) whether micro- or macropolitical conscientization (Freire, 1998) at the individual level is necessary for systems-level organizational learning and development and (b) whether transformative change at both of those levels is a necessary condition for second-order community change. The evidence here is more complicated. Two of the three organizations managed to engage in some degree of second-order community change with, at best, very inconsistent internal learning organization practices, but that inconsistency may have contributed to their inability to address community conditions in an effective and sustained way. In the case of Community Faith Network, the rigidly hierarchical organizational structure at the top and in its relations with its national umbrella organization may have served to support its second-order community change mission, but failed to live up to the organization's democratic ideals and mission and potentially undermined its capacity to build a sustainable and effective coalition. The learning opportunities at CFN were not only faith- and issue-based, but political, economic, and social systems-oriented, including plenty of rhetoric about equity and justice. It may be unrealistic to expect any organization to fully adhere to its own rhetoric, but that is why attending to the message being presented and learned at multiple levels is important. If CFN had paid as much attention to its organizational learning and empowerment processes and structures as it did to its community change message, it might be in a stronger position today. Although these data do not prove that second-order community change requires learning organization practices, they clearly suggest that having a community change mission and a large number of energetic volunteers is not enough, and that organizational capacity is also very important.

On the other hand, we also found that organizational learning is not a sufficient condition for transformative community change, nor did we expect it to be. St. Daniel's had instituted effective mechanisms and structures for learning and adaptability and provided direct human services that were outwardly effective. That very success in first-order community change seemed to give staff, volunteers, and community members involved with the organization a strong sense of community and feelings of empowerment. Yet as laudable as those achievements are, and as important as those services may be to recipients, 
they did not significantly change the material conditions of community residents, address the root causes of their problems, or make the overall distribution of power or other resources more equitable. The engine of the organization relied on sources of funding for specific programs. These grants all required individual output and outcome data for renewal. Thus, the game for many nonprofits is necessarily ameliorative. There are fewer sources of revenue for efforts that focus on community structural conditions. This raises the question of to what extent such organizations contribute to the maintenance of the status quo.

At the individual level, all three organizations offered opportunities not only for role and task-related learning, but also for some form of personally transformative learning. The type of such learning varied and was linked to each organization's change focus. In City Space, staff, board members, and other volunteers participated in regular forums to discuss both general and specific urban planning topics. In Community Faith Network, learning was more justice issue-oriented and political, but opportunities for most members were too infrequent. In both organizations, a moderate level of transformative individual learning and empowerment did not result in a systemic "learning organization." Transformative learning opportunities were most consistently available at St. Daniel's and were connected to opportunities for participation in organizational roles and decision making.

Although not original, an important observation is that organizational change and stability, or sustainability, are interdependent, or in dialectical relationship with one another. In order to reach its longer term goal of sustainability, an organization may need to facilitate transformative learning and change. Individuals and organizations need to continually learn and develop so as to respond effectively to their changing environments. It may be less obvious whether an organization's long-term viability depends on second-order community change. Organizations engaged in first-order (ameliorative) community change often grow and become institutionalized because that is the reigning paradigm and they are rewarded for services that essentially preserve the status quo. By the same token, second-order change is difficult, often leads to disappointment and frustration, is rarely funded, and in the relatively rare cases where it is successful, it may even lead to an organization putting itself out of business if the members feel they have accomplished all they set out to, or at least enough. This is also where the learning organization literature may be helpful in its understanding that in a dynamic context, sustainability and change are not mutually exclusive; that transformative individual and organizational learning and empowerment build an organization's capacity to adapt and change, but also survive, in a complex, harshly competitive, and ever shifting environment. Ultimately, however, the emphasis of our framework on second-order change is based on community psychology's own stated value that changing the underlying conditions that contribute to problems in people's lives is better than spending all of society's available resources on maintaining the status quo through inadequate services.

\section{Strengths and Limitations}

Our findings should not necessarily be generalized to other organizations. Even for these three organizations, analyses are based on just a handful of interviews and varying numbers of participant observations (ranging from just a few by one coauthor at St. Daniel's to well over 50, plus other communications, by three coauthors at City Space ${ }^{4}$ ). They are 
more than mere static "snapshots," however, especially at City Space and Community Faith Network, where observations began over three years ago and are still ongoing. It is possible, however, that our shorter-term, less thorough, more "outsider" knowledge of St. Daniel's may have led to a less critical view of its internal organizational strengths.

It is important for organizational research methods to be ecologically valid, which implies several things to which we have tried to attend. One implication is the consideration of phenomena at multiple levels, including the extraorganizational context. We have obviously taken those levels and the community context very seriously. It also helps to use multiple methods, which we have done, although here, concentrating mainly on the qualitative interviews and observations. For some, ecological validity also implies a phenomenological orientation, which we have tried to emphasize by providing direct quotations. Rather than take a purely interpretive analytical approach, however, we used an eclectic epistemological orientation, drawing on elements of critical, postpositivist, and constructivist, or interpretive, approaches (Guba \& Lincoln, 1994; Lee, 1991).

Yet another ecological research objective is to capture change over time. Community organizations are, by nature, more fluid and dynamic than large public or private institutions. The danger of this is that the very survival of community organizations is often at stake. The advantage of fluidity, however, is that it provides participants frequent opportunities to diagnose the organization and realistically change it in fundamental ways. We believe our cube framework may provide community organizational researchers and administrators with a simple, graphic diagnostic tool to assess how learning and change are happening and could be improved at each level—individual, organizational, and community-and whether the learning and change are merely ameliorative or truly transformative. Several organizations in the larger study (not included in this paper) that were chosen because they had a reputation as being leading nonprofits in the community turned out to be very low functioning and were fraught with organizational problems. These organizations, at best, focused on individual task or skill learning, were reactive and incremental in the way the organization adapted and learned, and had as their mission to improve the lives of target populations through direct services to individuals. If participants of such organizations honestly confronted where their organization is in terms of learning and change at all three levels, they would have to place it in the lowerleft front corner of the cube. We found no organization that we could place in the upperright back cell of the cube, which should give virtually any organization a clear sense that there is more transformational work they could do at one or more levels.

\section{The Role of Power}

An important caveat to this study is that the role of power has been only marginally addressed. Our purpose in this paper has been to examine the mechanisms of organizational learning in three different organizations where such processes were believed to be functioning. This approach, we believe, is appropriate given the relative dearth of empirical studies on the topic, especially in community nonprofit and voluntary organizations.

Nevertheless, social power, both within organizational settings and within the communities in which these organizations are embedded, has a tremendous influence on the phenomena of organizational learning. This impact is especially relevant given the normative role that "community change" is provided here. We acknowledge the very limited attention to power provided in this paper, yet hold that greater attention must be paid to this issue in future research. 
Finally, two key issues around power surfaced in this research and are worthy of note. First, the relative powerlessness of individual nonprofits within the broader community context makes the goal of community change extremely difficult. This is particularly true for service-providing agencies that may be extremely vulnerable to funding entities. These funders may also be the targets for change, thus "transformative change" at the community level may mean alienating one's funding base. Second, within organizations, hierarchical structures are the norm, and the power and positional authority within such settings will not likely sanction learning that is expansive to the point of questioning roles, power, and decision making. This may explain why organizational learning is conceptualized as occurring at the group and organizational level, but in the literature, it is often, of necessity, operationalized as aggregate individual learning. The fact that this is how organizational learning is considered in practice may reflect the power dynamics within organizations, that is, those holding power within organizations are tied to the status quo when it comes to roles, decision making, and power. That is why our questions focused so heavily on those issues.

\section{CONCLUSIONS}

This paper makes several contributions to the literature. First, it begins to address the gap in research on organizational learning in nonprofit settings. The data from our study suggest that those few nonprofits that implemented learning organization strategies had greater organizational capacity and weathered changes in the external environment much more easily. Yet we found that many of the organizations we studied were lacking the structures and processes to support organizational learning. Second, by studying organizational learning through an empowerment lens, we illuminated an aspect that has received less attention in the management literature but has been of central concern in community psychology. This research examined both individual-level psychological and material empowerment and organizational-level resource exchange. Although it remains unclear whether higher level change is necessarily dependent on change at lower levels, our analysis does suggest that human capital capacity development makes a difference-those organizations that empower staff and volunteers at the individual level through opportunities for learning and participation fare better in terms of organizational- and community-level learning and transformation. This is consistent with organizational learning theorists' and community psychologists' belief that greater participation and empowerment make organizations more effective both in their internal operations and in serving the community. Finally, this study employed an ecological framework, studying the relationship among individual-, organizational-, and community-level phenomena. By examining differences across levels and organizational contexts in what leads to first- and second-order change, this study began to address the need to understand the complex role organizations play as mediators of community change.

Future research must establish effective intervention methods to help nonprofits create new structures, processes, and cultures for the learning, development, and empowerment of members and clients, of the organization as a whole, and of the community it serves. This has been attempted with limited success through relatively "low-dose" datafeedback consultations with small, local voluntary associations (Florin, Chavis, Wandersman, \& Rich, 1992). A more promising approach may be a new action-research project by Prilleltensky and colleagues (in press) using more intensive and ongoing consultations that focus on building strengths, primary prevention, empowerment, and changing 
community conditions with larger, United Way human service organizations. As our case studies show, moving from ameliorative to transformative interventions at multiple levels is not easy work, but is essential if community psychology is ever to live up to its own values.

\section{REFERENCES}

Addleson, M. (2000). What is good organization? Learning organizations, community, and the rhetoric of the bottom line. European Journal of Work and Organizational Psychology, 9(2), 233-253.

Argyris, C. (1993). On organizational learning. Cambridge, MA: Blackwell Publishers.

Argyris, C. (1994). Good communication that blocks learning. Harvard Business Review, July-August, 77-85.

Argyris, C. (1997). Initiating change that perseveres. American Behavioral Scientist, 40(3), 299-309.

Argyris, C., \& Schon, D. (1996). Organizational learning II: Theory, method, and practice. Reading, MA: Addison-Wesley.

Bateson, G. (1972). Steps to an ecology of mind: Collected essays in anthropology, psychiatry, evolution, and epistemology. San Francisco: Chandler.

Brown, B.B., \& Perkins, D.D. (1992). Disruptions in place attachment. In I. Altman \& S. Low (Eds.), Place attachment (Vol. 12, pp. 279-304). New York: Plenum.

Brown, J.S., \& Duguid, P. (1991). Organizational learning and communities-of-practice: Toward a unified view of working, learning, and innovation. Organization Science, 2, 40-57.

Christens, B., \& Perkins, D.D. (in press). Transdisciplinary, multilevel action research to enhance ecological and psycho-political validity. Journal of Community Psychology.

Cook, S.D.N., \& Yanow, D. (1993). Culture and organizational learning. Journal of Management Inquiry, 2, 373-390.

Coopey, J. (1995). The learning organization: Power, politics, and ideology. Management Learning, 26, 193-213.

Cyert, R.M., \& March, J.G. (1963). The behavior theory of the firm. Englewood Cliffs, NJ: Prentice-Hall.

De Vita, C.J., \& Fleming, C. (Eds.). (2001). Building capacity in non-profit organizations. Washington, D.C.: The Urban Institute.

Easterby-Smith, M., Snell R., \& Gherardi, S. (1998). Organizational learning: Diverging communities of practice? Management Learning, 29(3), 259-272.

Fisher, S.R., \& White, M.A. (2000). Downsizing in a learning organization: Are there hidden costs? The Academy of Management Review, 25, 244-251.

Florin, P., Chavis, D.M., Wandersman, A., \& Rich, R. (1992). A systems approach to understanding and enhancing grassroots organizations: The Block Booster Project. In R. Levine \& H. Fitzgerald (Eds.), Analysis of dynamic psychological systems (Vol. 2, pp. 215-243). New York: Plenum.

Freire, P. (1998). Cultural action and conscientization. Harvard Educational Review, 68(4), 499-521.

Friedman, V.J. (2001). The individual as agent of organizational learning. In M. Dierkes, A.B. Antal, J. Child, \& I. Nonaka (Eds.), Handbook of organizational learning and knowledge (pp. 398-414). New York: Oxford University Press.

Gherardi, S., Nicolini, D., \& Odella, F. (1998). Toward a social understanding of how people learn in organizations: The notion of situated curriculum. Management Learning, 29, 273-297.

Guba, E.G., \& Lincoln, Y.S. (1994). Competing paradigms in qualitative research. In N.K. Denzin \& Y.S. Lincoln (Eds.), Handbook of qualitative research (pp. 105-117). Thousand Oaks, CA: Sage. 
Hager, M. (2001). Explaining demise among nonprofit organizations. Nonprofit and Voluntary Sector Quarterly, 30, 795-797.

Herman, R.D., \& Renz, D.O. (1999). Theses on nonprofit organizational effectiveness. Nonprofit and Voluntary Sector Quarterly, 28(2), 107-127.

Kasl, E., Marsick, V.J., \& Denchant, K. (1997). Teams as learners: A research-based model for team learning. Journal of Applied Behavior Management, 33(2), 227-246.

Keys, C.B., \& Frank, S. (1987). Community psychology and the study of organizations: A reciprocal relationship. American Journal of Community Psychology, 15, 239-251.

Lave, J., \& Wenger, E. (1991). Situated learning: Legitimate peripheral participation. Cambridge, England: Cambridge University Press.

Lee, A.S. (1991). Integrating positivist and interpretive approaches to organizational research. Organization Science, 2, 342-365.

Levitt, B., \& March, J.G. (1988). Organizational learning. Annual Review of Sociology, 14, 319-340.

Marsick, V.J. (2000). Learning organizations. In V.J. Marsick, J. Bitterman, \& R. van der Veen (Eds.), From the learning organization to learning communities toward a learning society (pp. 5-19). ERIC Document Reproduction Service Information Series No. 382.

McHargue, S.K. (2003). Learning for performance in non-profit organizations. Advances in Developing Human Resources, 5(2), 196-204.

Miner, A., \& Mezias, S. (1996). Ugly duckling no more: Pasts and futures of organizational learning research. Organization Science, 7(1), 88-99.

Mojab, S., \& Gorman, R. (2003). Women and consciousness in the "learning organization": Emancipation or exploitation? Adult Education Quarterly, 53(4), 228-241.

Pawlowsky, P. (2001). The treatment of organizational learning in management science. In M. Dierkes, A.B. Antal, J. Child, \& I. Nonaka (Eds.), Handbook of organizational learning and knowledge (pp. 61-88). New York: Oxford University Press.

Peterson, N., \& Zimmerman, M.A. (2004). Beyond the individual: Toward a nomological network of organizational empowerment. American Journal of Community Psychology, 34, 129-145.

Prilleltensky, I. (in press). The role of power in wellness, oppression, and liberation: The promise of psychopolitical validity. Journal of Community Psychology.

Rhodes, C. (2002). Facilitating learning organizations: Making learning count. Journal of Occupational and Organizational Psychology, 75, 252-254.

Schein, E.H. (2004). Organizational culture and leadership (3rd ed.). San Francisco: Jossey-Bass.

Senge, P. (1990). The fifth discipline: The art and practice of the learning organization. Chatham, MA: Doubleday.

Shinn, M., \& Perkins, D.N.T. (2000). Contributions from organizational psychology. In J. Rappaport \& E. Seidman (Eds.), Handbook of community psychology (pp. 615-641). Dordrecht, Netherlands: Kluwer Academic.

Snell, R., \& Chak, A. (1998). The learning organization: Learning and empowerment for whom? Management Learning, 29, 337-364.

Speer, P.W., \& Peterson, N.A. (2000). Psychometric properties of an empowerment scale: Testing cognitive, emotional, and behavioral domains. Social Work Research, 24(2), 109-118.

Tsang, E. (1997). Organizational learning and the learning organization: A dichotomy between descriptive and prescriptive research. Human Relations, 50(1), 73-89.

Watkins, K., \& Marsick, V.J. (1993). Sculpting the learning organization. San Francisco: Jossey-Bass.

Watzlawick, P., Weakland, J.H., \& Fisch, R. (1974). Change: Principles of problem formation and problem resolution. New York: Norton.

Wenger, E.C., \& Snyder, W.M. (2000). Communities of practice: The organizational frontier. Harvard Business Review, 78, 139-145. 


\section{FOOTNOTES}

${ }^{1}$ As discussed above, group or team learning represents an important level that serves to bridge individual and organizational learning and which should be carefully studied. We reluctantly chose not to try to represent the group level in our framework for the sake of simplicity and the difficulty of graphically illustrating more than three levels.

${ }^{2}$ All names of organizations are pseudonyms.

${ }^{3}$ It should be noted that this organization has undergone a change in both staff and management since these interviews were done.

${ }^{4}$ One coauthor served as an unpaid intern at City Space, another served on the steering committee of one of its main programs and frequently participated in its forums, and a third attended occasional forums. Four of the coauthors participated in a few Community Faith Network meetings or activities; two of those four played key supportive roles in one of its initiatives. As with any ethnographic research, especially those involving participant observation, there is a chance that this level of involvement may have biased our perceptions of those two organizations. We have tried to be as objective as possible in our assessments of each organization, however, and the fact that multiple authors were able to cross-validate their experiences and impressions of those two organizations adds to the reliability of our findings. 